a good man's life has been wrecked by loss of selfcontrol on one occasion only-when he has indulged in excess of àlcohol.

Control of the liquor trafflc, especially of the sale of spirits, is necessary in the public interest, but I do not favour total prohibition. The sale of alcoholic beverages in the form of light beers and wines seems to be a reasonable mode of dealing with the question, and not likely to cause the widespread discontent that total prohibition would.

Mental Hygiene and the Teaching of Psychological Medicine.

In America, for the past three years, there has been a very active development in the study of mental hygiene, and a quarterly journal dealing with the subject in all its aspects has been published by a National Committee of Mental Hygiene of which Mr. Clifford Beere is the secretary. He wrote a remarkable book entitled "A Mind that Found Itself." In this he gives his experiences of the treatment of his mind when it was unsound, and points out how illogical it had been. The objects of this national committee are to help both the physician and the patient; also to befriend the patient's relatives, to whom, when burdened with an actual or impending affliction, it would become an unfailing source of information, advice, or comfort. In a word, it would be a friend to humanity, and upon these lines this Committee of Mental Hygiene and its centres of activity have been doing most valuable work in the United States. It is such a "Before-Care Association" that we want in this country.

The war has shown the great need of systematic teaching of psychological medicine as a part of the medical curriculum. In 1907 (Vol. III., Archives of Neurology and Psychiatry) I strongly advocated this teaching for post-graduates, and suggested that a diploma of psychological medicine should be instituted, for I felt sure that it would raise the tone of medical men employed in the care of the insane and lead to diagnosis and better treatment of mental disease in the early curable stage. I also advocated the establishment of a psychiatrical clinic in London, where the incipient and borderland cases could be seen and treated.

In a recent number of THE LANCET, ${ }^{1}$ in an annotation on the Genesis of the Maudsley Hospital, the statement I made is quoted in full, and the article goes on to say that there is good reason to believe that it was this desire on my part to see a hospital in London for the study and treatment of neuroses and insanity in the early stages which induced Dr. Henry Maudsley to give $£ 30,000$ to the L.C.C. to build such a hospital. Unfortunately, this great physician, philosopher, and philanthropist died a few years ago, before the hospital, which is named after him, was fulfilling the objects which he contemplated. However, it did most valuable service during and after the war, and I hope that soon the Ministry of Pensions, who are at present using it, will be able to hand it over for civil use. I was convinced in 1907 that the institution of a diploma in psychological medicine would prove as valuable to that branch of medicine as the diploma of public health had been, and I called upon the President of the Royal College of Physicians to try and induce the Royal Colleges to give such a diploma, but I was quite unsuccessful. Just prior to the war the Cambridge University led the way and instituted such a diploma, and now many universities and the Royal Colleges give diplomas of psychological medicine. What is now required is the systematic teaching of the subject. For the past three months a course of psychological medicine, which will occupy six months, has been in operation at the Maudsley Hospital, under the direction of the L.C.C. The course has been designed for either the University of Cambridge diploma or for that of the Royal Colleges. I am pleased to say that a class of 36 post-graduates have attended.

The Neglect of Medical Psychology.

Sir George Newman, in his recent admirable report on Medical Education, states: It is deplorable that the English student of medicine should have no oppor-

1 THE LANCET, March 13th, 1920, p. 618. tunity of learning modern methods of psychiatry or of diagnosing incipient and undeveloped cases of mental disease. And yet, in 1913, Parliament imposed statutory duties upon the medical practitioner, among them being: "He must be competent to diagnose all forms of mental disease" (Mental Deficiency Act, 1913). The public might ask, why did not the authorities previously insist upon proper training in this important branch of medical education, involving the liberty of the subject? The effects of this neglect of training in this important branch of medicine was shown in conscripting for the war. In the report of the Ministry of National Service physical fitness and unfitness only are considered.

It is difficult to understand, in the face of the report of Sir George Newman and war experience, that in the report of the Consultative Council on Medical and Allied Services, the scheme referring to the equipment of the Secondary Health Centres, Provision 57, does not include any department of neurology and psychiatry, although other and less important special departments of medicine are provided thus: skin, ear and throat, eyes, genitourinary, dental, and industrial hygiene. Possibly, having regard to the fact that $D r$. Addison, in a preface to $\mathrm{my}$ work on "Shell Shock and War Neuroses," fully recognises the importance of the subjects, the Ministry of Health may have in view some special scheme of dealing with neurology and psychiatry.

The importance of psychotherapy has been realised in the university of this great city, for courses of lectures have been given on this important subject by two leading authorities, Dr. Bernard Hart and Dr. W. McDougall. Academic psychology is not of practical importance to the medical man, although the knowledge of it is helpful; it is the study of conduct and its disorders considered biologically, as set forth by the late. Dr. Mercier, which should engage his attention, and in conclusion I would remind my audience of the words of Francis Bacon, in his "De Augmentis," when he pleads. for a study of mind and character : "That so we may. have an accurate dissection of men's minds and characters, and the secret dispositions of particular men may be revealed, and that from a knowledge thereof better rules may be made for the treatment of the mind."

\section{SOME ASPECTS OF}

\section{FUNCTIONAL NERVOUS DISEASES.}

BY E. D. MACNAMARA, M.A., M.D. CAMB., F.R.C.P., PHYSictan FOR MENTAL disoRders, CHARING CROSS hospital.

THE complicated, contradictory, and fluid views currently expressed as to functional nervous diseases, affections bordering upon definite mental disorder and established insanity, must prove exceedingly bewildering, not only to the practitioner of general medicine, but also to those who particularly devote themselves to neurology and psychiatry. In the study of the rtiology of such affections it was not so long since that endless time and tireless energy were devoted to the search for structural alterations of tissues examined post mortem and to the examination of the cytology and chemical composition of such fluids as are available for examination during life. Fven now laborious works are being compiled and published full of descriptions of minute changes in the cells and in the chemical composition of fluids derived from cases of nervous and mental disease, but more striking, at least in bulk and novelty of content, is the gigantic output of literature of the last 20 years bearing upon psychology, normal and morbid, which contains little or no reference to anatomical findings and indeed not infrequently explicitly ignores them. The mind has come to be regarded as almost independent of the body, while the investigation of its processes is carried on solely in the psychological field. Many symptoms which not long ago were held to be due to faulty biochemical reactions are now ascribed to the ill-adaptation of mental processes. 
Anyone who has watched phases of the development of medical science and art will have been struck by the similarity of the genesis of fashions in therapy. A new idea is mooted and is almost at once carried to logical extremes by those who are of the imaginative and sanguine type of mind which especially loves "to tell or to hear some new thing." For instance, I remember when some years ago I set forth in a paper that a certain micro-organism had been discovered in a case of a certain disease, that $I$ received the day after publication a wire asking for a curative serum for use in its treatment. On the other hand, we find a type of mind common and probably more widely diffused, though as a rule less voluble, which strongly and almost angrily resents the upset and readjustment of ideas involved in novelty. There is a third type, of which there are but few examples, in which criticism follows hard upon discovery, and in which ardour for the hypothetical is moderated by patience and cooled by experience. The protagonists clash in that which is obviously a welcome conflict and the din is deafening, while the small voice of genuine inquiry is only heard when they are exhausted by their vociferations or have found some new thing to interest them. In the field of functional nervous disorder we are still in the midst of the battle, but it may be worth while to attempt very briefly to set forth the position to which we have been carried.

Disease With or Without Structyral Alteration.

By organic disease we mean that some alteration of structure has occurred, and that this alteration has been assoeiated with a disturbance or cessation of function. There are also disorders in which structural alteration is not at all obvious, but of which physical agents are generally recognised as the cause, for instance, the affections which result from intoxication either by bacterial products or by poisons of other origin, from the effects of climate, or from those numerous circumstances which result in symptoms of exhaustion. In these affections in order to produce a enre it is generally enough to remove the causative agent. There remain, however, disorders of the various systems of the body in which structural alterations have not been decisively demonstrated, and about which the opinion is general that there may be none to demonstrate. In these disorders ætiological factors are obscure and do not appear to include physical agents among them, while physical agents used therapeutically appear to be of little or no value. The literature of the last century is strewn with the endeavours which were continnously being made to discover among physical agents the causes of functional nervous disease, and innumerable physical agents, including drugs, hydrotherapy, electrotherapy, rest, isolation, diet, climate, gymnasties, and metals were used in their treatment. So many and divergent have been these methods that some suspicion has been aroused as to the value of any of them. Confusion hasalsoarisen from the fact that an agent apparently of value in some cases and in some hands has produced little or bad or no effect in other cases of a geemingly identical character. The problems which have thus arisen have of necessity tuined men's minds in another direction, and it has been sought to discover whether mental processes might not, at least in some cases, eventuate in physical disorder, and whether many somatic symptoms might not be in fact the expression of disordered mental operations. These surmises were fortified by a consideration of the many therapeutic systems mostly extra-scientific and practised by those who were not trained as professional physicians. Miracles of undoubted authenticity and gennineness have been recorded from the earliest times, and though sometimes associated with physical agents have not been associated causally with them and have appeared for the most part to have been produced by the effect of the expression of the performer's mentality upon his patient. During the early part of the nineteenth century, owing to the work and reputation of Mesmer, the idea of the mind cure became extremely prominent, and various synonyms for mesmerism, such as hypnotism and suggestion, have marked attempts to raise the empiricism of Mesmer's pro- cedures to a more scientific level. In the latter part of the last century arose the colossal movement known as Christian Science, the basic idea of which is the supremacy of the mind in its own and in the physical flelds. In this case also the endeavour to raise empiricism to a scientific level has been an important stimulus of psychological research in the causation and cure of the somatic effects of psychic disturbance, and in the essential character of the disturbances themselves. Whether the causation of any affection be regarded as of physical or psychic origin, general principles of treatment still hold good-that is to say, the discovery, where possible, of the exciting cause and its removal, the neutralisation of its ill-effects, or where this is not possible, their palliation.

The therapeutic principle of palliation of symptoms of psychic origin is perhaps best exemplified by the method derived from the Stoics of inducing in the patient's mind a contempt of his bodily suffering, and a reliance on such fortitude as he can muster. The neutralisation of symptoms is exemplified by the method of suggestion under hypnosis in which injunc. tion not to have certain symptoms sometimes results in their disappearance. The most truly radical mode of treatment, however, lies in the attempt to discover the mental irritant and to remove it. These modes of treatment have each of them ardent exponents, and any one of them would appear from currentliterature to be capable of the cure of all functional nervous diseases. In practice, however, these methods are discovered to be inextricably confused, to overlap and not by any means always to eventuate in the hoped-for results, while the time and labour involved both for patient and physician not infrequently render them impracticable.

Physico-genetic and Psycho-genetic callses.

The causes of functional nervous disease may be divided into those which are physico-genetic and those which are psycho-genetic. Among the physico-genetic causes are the toxins of the bacterial infections and of intestinal stasis, the poisons manufactured in the body by faulty metabolism, as in gout and diabetes, poisons taken into the body, for instance, alcohol and morphia, and the excessive or defective amount of the secretion of the endocrine glands or its defective quality.

The psycho-genetic origin of certain functional nervous and mental disorders has been long and universally recognised. Before the physico-genetic causes were in the last century especially stressed, delirium, mania, melancholia, and delusions had been regarded sometimes as due to direct possession by the devil, and at others as the punishment of $\sin$ or the manifestation of a guilty conscience. The pendulum has again swung in this direction, though nomenclature has altered. Possession by the devil is not held to be a causative factor of functional nervous disease, but mental conflicts as the result of the opposition, on the one hand, of instinct, and on the other of education in its broadest sense is, in some quarters, held to be the basic and often the sole cause. It is a platitude to say that certain events make a more powerful impression than others, and that certain ages are more impression able than others. Some events make such an impression that they are associated with the phenomena of physical "shock." Persons who have been shocked in this way often show symptoms which before the war were grouped under the heading of traumatic neurasthenia, and which during the war were given the euphemistic name of "shell shock." Other events do not produce shock but changes of a more subtle character, which may eventuate in states of mind which are not compatible with the instinctive and acquired mentality of the individual. Such states of mind may betray themselves in varions ways as symptoms. In some such cases the origin of the symptoms may not be known by the patient, or a supposed origin may not be the true one. As a rough analogy derived from the somatic field may be mentioned the common experience that the dyspeptic often attributes his symptoms to heart disease, and is proportionately depressed by them, and that when their true origin is explained to him he sees how baseless and 
unreasonable is the anxiety from which he had been suffering. In addition to the dramatic causation of cases of traumatic neurasthenia and shell shock, there are in all lives potentialities of worry-that is, of mental discomfort, distress, or even pain. Worry may be associated with the home, with the health and character and conduct of relations and friends, with their attitude towards the patient or with his towards them; with the patient's professional career, with the making of name and position; with society, its congeniality or uncongeniality, or with the level which it has assigned to the patient or with the level in it to which the patient aspires; with religion, dissatisfaction with a faith and insufficient faith or scepticism, or the incompatibility of past or present conduct with some ideal standard; with politics and the incompatibility of things as they exist with the imagination of what they ought to be. Such factors as these are often very well known to the patient as sources of worry and as producing disharmony and conflict in his mind. Palliation, neutralisation, or complete abolition may be obtained by amended attitudes of mind and conduct. In some cases, however, the symptoms which take the patient to the physician are not recognised as the result of the worry, or, maybe, the mental disharmony or distress or conflict is not patent and explicit in his mind, and he is only brought to recognise it when the incongruities of his mentality are brought to light and become plain to him. Such an absence of clear recognition on the patient's part of his own mental disturbance may be of the nature of a defence against psychic discomfort or pain, and, in fact, due to the putting aside or repression of that of which the presence is not desired in consciousness. The process of repression appears to imply (1) an un. pleasantness or a something to be repressed; (2) a tendency to forget the unpleasant, not necessarily consciously acknowledged, and which would, when it acts very early in life, seemingly amount to an instinctive process; (3) a power to put this tendency into operation and to make it effective; and lastly (4) that which may be called a mechanism of repression, the nature of which is not at present completely understood. That repression is not always absolutely complete is obvious, for if it were no past unpleasantness, whether remembered or not, would cause either mental distress or those symptoms which are alleged to be the expressions of unconscious conflict.

\section{Mental Degeneration, General or Patchy.}

In organic mental affections-e.g., general paralysis of the insane, chronic alcoholism, or arteriopathic dementia-there occurs a general all-round mental degeneration. In functional affections the symptoms are not those of an all-round degeneration, but are of a patchy distribution; for instance, there may be imperative ideas, obsessions, delusions, amnesia, morbid anxiety, phobia, anæesthesiæ, palsies, contractures, or such abnormal movements as tremors and tics. It would hardly seem worth while to explore the psychic rtiology of the symptoms of general paralysis, while it is as obvious that the exploration of the psychic factors of the rtiology of such symptoms as those just named must be very important. It should, however, always be remembered that various conditions of lowered physical health make symptoms of psychic origin more pronounced, and in many cases appear to be their direct excitant. This is also especially important in treatment, since the facilities at present obtaining in most neurological clinics as now conducted for prolonged mental examination are but small, and recourse has to be made to some of the crude though useful methods of physicotherapeutics. It is not proposed here to review such methods for the treatment of functional nervous disorders. Rest, isolation, electro-therapy, balneo-therapy, drugs, and careful dieting have their place as useful adjuvants of psycho-therapy in various cases, and as forming a scenic setting for its performance. With regard to modes of treatment whose object is to deal directly with morbid phenomena patently or not of purely mental origin, there are three which command the most attention-namely, suggestion, education or re-education, and analysis.
Three Mlodes of Treatment: (1) Suggrstion.

A definition of suggestion has not been generally agreed upon. The term is used in many different senses. The primary meaning of suggestion is the putting forward of an idea with a view to its acceptance by the individual to whom it is proposed. Plainly the methods of proposition may be very varied, but perhaps it is correct to say that in medicine the term means the authoritative propositian of an idea for acceptance without question. Suggestions may be made when the patient is in a condition of artificial sleep or in the waking state. During hypnosig the patient's conscious mind is at rest and suggestions are made to the part of the mind which is not conscious. On the other hand, in the waking state suggestions are made to a part of the mind in which, as it is hoped, criticism is not aroused and in which there is a mental attitude of passive acceptance and obedience. Such appeals to the unconscious or to the unraflecting mind may undoubtedly, at least in some cases, mitigate or abolish symptoms. But it is obvious that in such a method the origin of the symptoms is not explored and their cause persists. There is probably a state of what may be called normal suggestibility, which is the usual one for most individuals, and it is to this normal state that political orators and newspaper editorials, directed towards the influencing of our "psychology," appeal. Most of our "opinions" are probably the result of various influences which have impinged upon us at impressionable periods of life and which are, in fact, founded upon but slight if any real ratiocination. There is also undoubtedly a condition of hyper-suggestibility in which some persons are prone to accept absurd propositions or those which are novel or extraordinary. When sick, or when they think they are sick, such persons try cure after cure simply because suggestion is made to them by advertisement or by enthusiastic friends that the various cures are infallible. It should here be remembered that an alternative name for hysteria is pithiatism, a word coined to express the opinion that hysteria is due to hyper-suggestibility. On the other hand, it is undoubtedly the case that some persons are hypo-suggestible. A few individuals are not prepared to accept propositions unless they are proven, an ideal state rarely, if ever, attained; while others have not reached this ostensibly high intellectual level, but are simply unreceptive of ideas to which they have not been accustomed or which they do not understand. Under treatment by suggestion may, perhaps, be placed a method which has come to be known as that of "shock tactics," in which a ferocious appearance, a hectoring manner, and ar faradic current are combined to assure the patient that he has nothing really the matter with him. Suggestion under hypnosis is also used to induce the expression of a mass of pent-up emotion, the result of some direful experience. The memory of the experience has been repressed, with resulting symptoms of functional nervous disease. The patient is told under hypnosis again to live through the experience. He does so, and in so doing gives vent to the emotional expression proper to the experience. Such purgation of his unconscious mind may result in the disappearance of symptoms.

(2) Education.

In the therapeutic applications of education or reeducation, in those cases where education has been defective or erroneous, appeal is not made to a mind which is not at the time conscious or under the spell of authority, habit, and custom, but is made to the developed and organised power of ratiocination. The appeal is generally by way of explanation and elucidation of symptoms, and an endeavour is made to arouse and develop firstly, a reasonable outlook, and secondly, the self-control which constitutes the normal repressing force. A method by which repression is effected and the power to repress doubtless exist and have been evolved because they have their value.

Just as the physical eye has, during evolution, learnt to see that which is useful for the purposes of the organism to which it belongs, and is neither microscopic nor telescopic in its powers, so has the osychic eye learnt to make its selections, while the rest is neglected as valueless or repressed for its unpleasantness. It is 
not, then, unreasonable to suppose that there is in the individual a proper amount of the power of repression, and that in some this power is weak and results in hyporepression, while in others it is strong and results in normal repression, or perhaps at times in over or hyperrepression. In hypo-repression that which it has been sought to repress may manifest itself in ways which are recognised by the patient as due to his defective power of repression or in ways which are not so recagnised, and are expressed as symptoms of functional nervous, disease. On the other hand, in hyper-repression in , persons of considerable power of ratiocination and self-control, there may, for a time at least, be periods during which symptoms disappear or are tolerable, but there are likely to be other periods when their powers are weakened, perhaps owing to physical illness or to exhaustion, and when that which is repressed may again emerge and indicate its presence in morbid anxiety, in various symptoms of functional nervous disease, or in the tremendous spiritual conflicts of which accounts are frequent in "Lives of Saints." In this mode of treatment, as in treatment by suggestion, the origin of symptoms has not been investigated.

(3) Analysis.

In one aspect mental analysis is but an elaborated and systematised method of investigating the causes of functional nervous disease, but by its radical methods it also claims to remove the causes of disease and in this way especially to be of therapeutic value. The treatment of symptoms is held, as in general medicine, to be of less value than the discovery and eradication of the causes of disease. These causes are -often of the nature of repressions, which occur in some cases so early that, as it has been observed, it is difficult to determine whether the process is an instinctive one or a result of early education. Repression certainly does occur later in life, when ideas which have been inculcated clash with instincts, or when one set of inculcated ideas clashes with another. In the latter case, at any rate, it is doubtful if it is necessary to carry an examination as far as infancy to discover the repressed idea. But in other cases it would appear that normal psychic growth has not been steadily progressive, and that in some respects it has become stationary, so that a conflict arises between this fixed set of ideas and other sets of ideas which have continued their normal progression.

Some of these fixations and repressions hinge upon the sexual impulse, but it is doubtful if in all cases it is necessary to insist upon such a connexion, at least if the word sexual is to be used in its customary sense. Recently the word has been given an extension which includes the "impulse towards life," relations between parents and children, and ordinary social relations between persons of the same or opposite sex. In the investigation of these relations it is somewhat difficult to avoid the feeling that too great a scope is occasionally allowed to the vagaries of the imagination, for they are extremely difficult to control in scientific investigation. In 'some cases, interpretations, seemingly wild, are confirmed, but occasionally also such interpretations appear to take the nature of a rather dangerous process of suggestion, the process being recognised neither by the patient nor the physician, and an imaginative interpretation is adopted by both and set forth as the canse of the disorder. Further, it is quite obvious to those, having experience of cases which have been systematically investigated that the discovery ensuing from the investigation does not always eventuate in cure, or, even alleviation. Failure to alleviate may be ascribed by the physician to his defective knowledge or faulty art, but when he comes across unrelieved cases which have been treated by the able, experienced, and learned, a similar doubt as to the correct nature of the technique cannot be raised, and he is obliged reluctantly to admit that this method, along with others at present in use, has its limitations.

From the practical point of view the time which a faithful analysis takes, owing to the numerous cross currents, false scents, and mare's-nests, often makes it impracticable as a form of treatment. Whatever the theory as to ætiology adopted, and whatever the mode of treatment practised, it remains true that many, and perhaps the majority, of those suffering from functional nervous disorders get better, and, indeed, happily often lose their symptoms entirely. Many cases have also recovered without any pretence of treatment, or their cure has occurred during a treatment which has not perceptibly been causally connected with it. The repressive forces have perhaps become stronger, or the expanding or centrifugal force of that which is repressed has perhaps become weaker. Inquiry into the nature and strength of such forces is very much needed.

The fruits of experience and thought tend, above all things, to show that psychology is still in its infancy and that morbid psychology is younger still, that we cannot do much therapeutically, but that we can do something, and that we certainly cannot afford in examining a case to leave any stone unturned or in treatment to leave any method untried, whether it be derived from the physical or psychic worlds. To make too hard-and-fast a division between the psychic and the physical is to go unwarrantably beyond the data of experience. As physicians we have to deal with the mind and with the body, and where the sphere of the one begins and the other ends we certainly do not know, nor to what extent, for good or evil, they influence each other.

\section{A CONTRIBUTION TO THE DIAGNOSIS OF}

\section{ACTITE PULMONARY TUBERCULOSIS}

BY JOHN B. MCDOUGALL, M.D. GLASG., M.R.C.P. EdIN., F.R.F.P.S. GLASG.,

CHIEF CLINICAL TUBERCULOSIS OFFICER, WEST RIDING OF YORKSHIRE.

AT the recent Tuberculosis Conference in Leeds it was admitted by the pioneer of auto-inoculation therapy in England, Dr. M. Paterson, that "borderline" cases have been met with occasionally in his own practice. The excellent results at Frimley, however, can only be ascribed to the consummate care with which the patients were selected for graduated exercise, for certain it is that success depends very largely on prolonged rest, graduated if need be, coupled with close clinical observations, in all cases exhibiting signs of active disease in the chest.

This borderline type of patient may be described as follows :-

The temperature is normal when the patient is at rest in bed, and very frequently also on rising to have light exercise in the ward. The pulse-rate fluctuates between 80 and 90 per minute, and may not be more than 95 after dressing. Cough and sputum may or may not be present, and the physical signs in the chest may vary from an apical lesion of small dimensions to extensive disease involving both sides of the chest. The sputum, if present, may show no acid-fast bacilli, or these may be present in small or large numbers. If it be washed and plated, however, it will almost invariably be found to contain secondary invaders in varying numbers and kinds.

Pneumococci and streptococci are common, but staphylococci, Micrococcus catarrhalis, and other organisms are frequently observed. The patient himself has a feeling of comparative well-being, and may complain of nothing except the ennui of restricted freedom. $\mathrm{He}$ is apparently fit and well enough to take a step forward in treatment. The first step may be a successful one, but more frequently it is followed by a rise in temperature, accompanied by the symptoms of uncontrolled auto-inoculation. Much, if not most, of the damage caused by indiscriminate tuberculin therapy has been in this type of case.

Leucocyte Counts giving Quantitative and Qualitative Cell Picture.

With a view to establishing an objective proof of latent activity in this " borderland" type the author" has carried out a large number of blood examinations, the details of which have been published elsewhere. I have found this helpful in guiding to a definite conclusion, one way or another, as to the suitability of a particular case for treatment by graduated rest and exercise.

The method is as follows:-

Total white cell counts are made at intervals during the day; blood examinations during the night are not necessary. 